\title{
SISTEM DETEKSI PLAT KENDARAAN DENGAN MENGGUNAKAN METODE K-NEAREST NEGHBOUR (KNN)
}

\author{
Farida $^{1,}$ Zahir Zainuddin ${ }^{2}$, Supriadi Sahibu ${ }^{3}$ \\ ${ }^{1}$ Sistem Informasi \\ STMIK Bina Adinata \\ faridahvaryd4@gmail.com \\ ${ }^{2}$ Teknik Informatika \\ Universitas Hasanuddin \\ zainuddinzahir@gmail.com \\ ${ }^{3}$ Pascasarjana Sistem Komputer \\ STMIK Handayani Makassar \\ http://pps.handayani.ac.id/ \\ supriadi.dit@gmail.com
}

\begin{abstract}
Abstrak
Sistem pemantauan dan manajemen kendaraan berbasis plat nomor kendaraan telah berkembang, Identifikasi dan pengenalan plat nomor menjadi aplikasi utama dalam bidang lalu lintas. terlalu banyak kejadian dalam berlalu lintas, salah satunya, seperti melewati batas stop di Jalan sehingga mengganggu para pengendara lainnya, hal ini paling banyak terjadi dan bahkan sering terjadi di kota-kota bahkan daerah sekalipun. Tujuan dari penelitian ini adalah untuk mengekstraksi dan mengenali plat nomor dari citra kendaraan yang melakukan pelanggaran sehingga dapat digunakan sebagai data set dalam membuat laporan penentuan sanksi yang sesuai dengan jenis pelanggaran kendaraan tersebut. Penelitian ini menggunakan proses ekstraksi pengolahan citra gambar sehingga metode yang sesuai dengan penelitian ini adalah K-Nearest Neighbour, dengan menggunakan metode tersebut akan memudahkan dalam proses pendeteksiannya. Karena metode ini tidak menggunakan perulangan. Prose ini dimulai dengan menyiapkan dari citra latih tahap kemudian melakukan tahapan pengenalan citra. Pengenalan citra merupakan proses mencocokan data citra digital yang sudah dirubah menjadi sebuah matriks kemudian dicocokan dengan dataset yang ada sehingga dapat diketahui hasilnya yang berupa laporan.
\end{abstract}

Kata kunci: Open CV, K-Nearest Neighbour

Abstrack
The monitoring system and managemen of vehicle have developed. Identification and number plat recognition in the field of traffic one of them is like passing the stop line on the road so that is disturbs other drivers, this is the most and even often occurs in big city cities even regions. The purpose of this study is to extract and recognize license plates from the image of the vehicle, that infringes so that it can be used as a dataset in making reports on determining sanctions that are appropriate to the type of violation of the vehicle. This study uses an image processing extraction process so that method according to this method is K- Nearest Neighbour, using this method will facilitate the detection process because this method does not use looping, this process begins by preparing a training image and then performing the image recognition stage. Image recognition is a process of matching digital image data that has been converted into a matrix and then matched with existing datasets so that the result can be known in the form of reports

Keywords: Open CV, K-Nearest Neighbour,

\section{PENDAHULUAN}

Deteksi plat kendaraan yang merupakan sistem pemantauan dan manajemen kendaraan berbasis plat nomor kendaraan telah berkembang, Identifikasi dan pengenalan plat nomor menjadi aplikasi utama dalam bidang lalu lintas. terlalu banyak kejadian dalam berlalu lintas, salah satunya, seperti melewati batas STOP di Jalan (Fadila, 2017) sehingga pelanggaran lalu lintas (Ruslianto \& Harjoko, 2013) ini 
mengganggu para pengendara lainnya, hal ini paling banyak dan bahkan sering terjadi di kota-kota bahkan daerah sekalipun. olehnya itu didesign pengelolaan citra pendeteksi plat kendaraan.

Tujuannya adalah untuk mengekstraksi dan mengenali plat nomor dari citra kendaraan yang melakukan pelanggaran sehingga dapat digunakan sebagai data set dalam membuat laporan penentuan sanksi yang sesuai dengan jenis pelanggaran kendaraan tersebut.

Telah banyak penelitian mengenai sistem pengenalan plat nomor dengan pengolahan citra Namun, dalam penelitian ini dikembangkan sistem pengenalan citra plat kendaraan setelah melewati batas stop dan hal ini mampu menjadi terobosan baru dalam ketertiban lalu lintas sehingga para pengendara mampu menjadi lebih tertib dan disiplin.

Penelitian ini menggunakan proses ekstraksi pengolahan citra gambar sehingga metode yang sesuai dengan penelitian ini adalah KNearest Neighbour (Sari, 2011), (Budianto, Ariyuana, \& Maryono, 2018), dengan menggunakan metode tersebut akan memudahkan dalam proses pendeteksiannya.

\section{METODE PENELITIAN}

Metode K-Nearest Neighbour (KNN) merupakan salah satu metode untuk melakukan klasifikasi terhadap objek berdasarkan data pembelajaran yang jaraknya paling dekat dengan objek tersebut. Tujuannya adalah untuk mengklasifikasikan objek baru berdasarkan atribut dan data training. Klasifikasi dilakukan tanpa menggunakan model tetapi hanya berdasarkan memori. Algoritma K-Nearest Neighbour menggunakan klasifikasi ketetanggaan sebagai prediksi terhadap data baru (Fauziah, Sulistyowati, \& Asra, 2019). Pada fase training, algoritma ini hanya melakukan penyimpanan vektor-vektor fitur dan klasifikasi data training sampel

\section{A. Rancangan Sistem}

Perancangan ini terdapat beberapa komponen yang saling berkaitan serta saling mendukung dan membentuk sebuah rangkaian. sistem ini rencananya akan dipasang di lampu merah lalu lintas dan juga mampu mendeteksi plat kendaraan, ketika kendaraan tersebut melakukan pelanggaran dalam artian melewati batas STOP lampu merah lalu lintas maka sistem akan langsung mendeteksi plat kendaraan tersebut kemudian dimasukkan ke dalam daftar kendaraan yang melakukan pelanggaran lalu lintas.

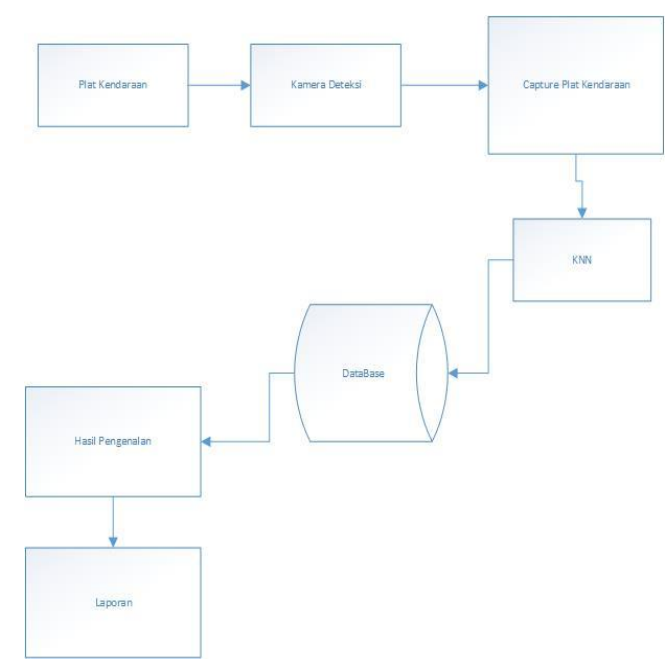

Gambar 1. Rancangan Sistem

\section{Jenis Penelitian}

kuantitatif

Penelitian ini menggunakan pendekatan

\section{Waktu dan Tempat Penelitian}

Penelitian ini direncanakan akan dilakukan di wilayah Bulukumba

\section{Target/Subjek Penelitian}

Target atau subject dari penelitian ini adalah Plat Kendaraan yang berwarna Hitam baik Kendaraan roda dua maupun roda empat.

\section{Data, Intrumen, dan Teknik Pengumpulan Data}

1. penelitian ke Perpustakaan (Library Research), yaitu pengumpulan data dengan cara membaca buku melalui literature, tutorial-tutorial maupun artikel dari internet yang bersifat ilmiah yang ada hipatitisnya dengan materi pembahasan.

2. penelitian Lapangan (Field Research), yaitu dilakukan dengan cara mengumpulkan data secara langsung kepada objek penelitian yaitu pada pembina atau guru yang bersangkutan dengan penelitian.

\section{Teknik Analisis Data}

Penelitian ke Perpustakaan (Library Research), yaitu pengumpulan data dengan cara membaca buku melalui literature, tutorial-tutorial maupun artikel dari internet yang bersifat ilmiah yang ada hipatitisnya dengan materi pembahasan.

penelitian Lapangan (Field Research), yaitu dilakukan dengan cara mengumpulkan data secara langsung kepada objek penelitian yaitu pada pembina atau guru yang bersangkutan dengan penelitian. 


\section{HASIL PENELITIAN DAN PEMBAHASAN}

Setelah citra telah disiapkan dari citra latih tahap selanjutnya perlu dilakukan tahapan pengenalan citra. Pengenalan citra merupakan proses mencocokan data citra digital yang sudah dirubah menjadi sebuah matriks kemudian dicocokan dengan data set yang ada sehingga dapat diketahui menjadi laporan (output) berupa text. Keberhasilan suatu pengujian dipengaruhi juga dengan jumlah data set yang dimiliki sehingga hasilnya sangat bergantung. Data set memiliki banyak varian sangat bagus karena tinggak kegagalan akan menjadi berkurang.

Proses dimana dilakukan untuk menghitung tingkat akurasi dari hasil pengidentifikasian citra plat nomor kendaraan pada mobil pribadi (plat warna hitam) dengan menggunakan metode $K$ Nearest Neighbour seberapa besar terjadinya kesalahan atau berapa besar terjadinya kebenaran dalam proses identifikasian tersebut.Adapun cara menghitung tingkat akurasi adalah sebagai berikut:

$$
\text { Akurasi }=\frac{\text { Jumlah prediksi benar }}{\text { jumlah total prediksi }} \times 100 \%
$$

Jumlah prediksi benar adalah jumlah record data uji yang diprediksi kelasnya menggunakan metode klasifikasi dan hasilnya sama dengan kelas sebenarnya. Sedangkan jumlah total prediksi adalah jumlah keseluruhan record yang diprediksi kelasnya (seluruh data uji). Metode klasifikasi berusaha untuk mencari model yang memiliki tingkat akurasi yang tinggi ketika model tersebut diterapkan pada data uji.

\section{A. Tahapan Pra Pengolahan}

Pra pengolahan melibatkan dua proses yaitu merubah resolusi dan mengkonversi ruang warna. Selain itu pengolahan juga melibatkan lokalisasi, lokalisasi ini berfungsi untuk memproses binarisasi dan mengubah citra kedalam bentuk black white, proses pengolahan inilah yang disebut sebagai thresholding atau tingkat kemiripan gambar.

1. Merubah citra warna

Dalam proses ini citra yang berwarna akan di ubah ke citra grayscale ( keabu-abuan ) Tujuannya adalah untuk mempermudah dalam pengidentifikasian citra plat nomor yang dibaca.

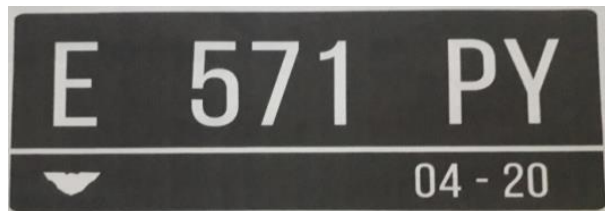

Gambar 2. Citra Plat Asli
Gambar 2 tersebut merupakan gambar citra asli sebelum di ubah ke bentuk grayscale ( keabuabuan ) bentuk hitam putih dari hasil pengolahan tersebut dapat dilihat pada gambar di bawah ini.

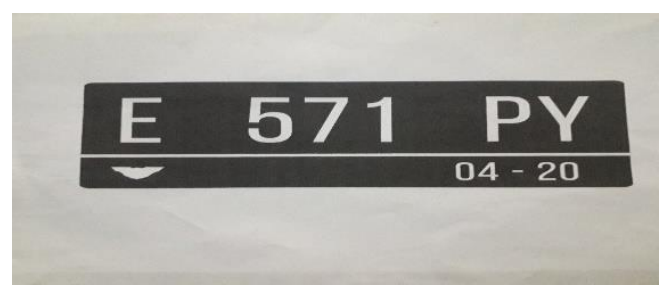

Gambar 3. Citra Plat Keabuan

Grayscaling adalah proses awal yang banyak dilakukan dalam image processing, hal ini dilakukan bertujuan untuk menyederhanakan model citra. Pada awalnya citra RGB umumnya terdiri dari 3 layer matrik yaitu R-layer, G-layer dan B-layer. Bila setiap proses perhitungan dilakukan menggunakan tiga layer, berarti dilakukan tiga perhitungan yang sama. Sehingga konsep itu diubah dengan mengubah 3 layer di atas menjadi 1 layer matrik grayscale dan hasilnya adalah citra grayscale. Citra ini tidak mempunyai elemen warna seperti citra sebelum diubah, melainkan mempunyai derajat keabuan.

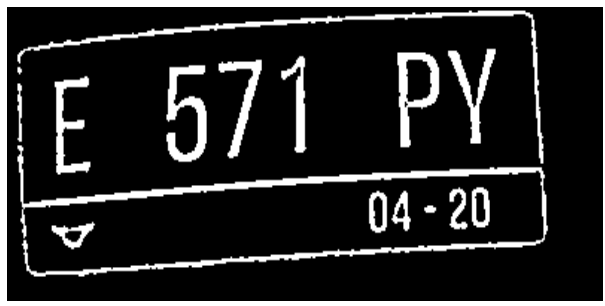

Gambar 4. Citra Hasil konversi biner

Setelah proses grayscaling maka dilanjutkan ke proses pengkonversian citra binary, setelah itu yang dapat menghasilkan pencarian nilai threshold atau tingkat kemiripan.

\section{B. Proses Pengenalan}

K-Nearest Neighbour (KNN) merupakan metode yang bersifat supervised dimana hasil dari query distance yang baru diklasifikasikan berdasarkan mayoritas kategori pada KNN. Pada vase training sample. Pada fase ini fitur-fitur yang sama di hitung untuk testing data ( jneis klasifikasinya belum diketahui ). Jarak dari vector yang baru ini terhadap seluruh vector training data sample dihitung. Dan sejumlah K buah yang paling dekat diambil beberapa analogi metode KNN :

a. Analogi metode klasifikasi KNN ( $\mathrm{K}$ - Nearest Neihgbour ) dimana $\mathrm{K}=1$ 


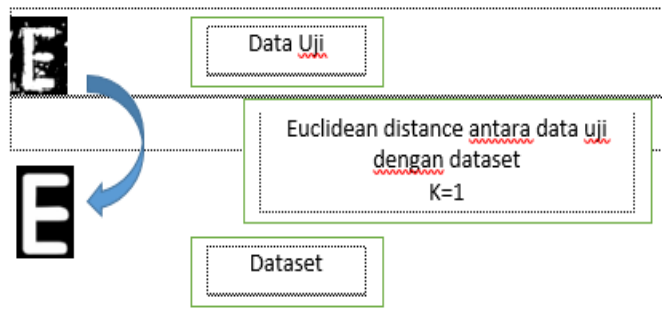

Gambar 5. Analogi KNN dengan $\mathrm{K}=1$

Dari gambar 5 di atas jelas terlihat bahwa data uji huruf E memiliki Euclidean 1 dengan huruf E yang berada di dalam dataset sehingga ketika melakukan pengujian data maka akan ditemukan hasil Euclidean distance antara data uji dengan data set yaitu 1 .

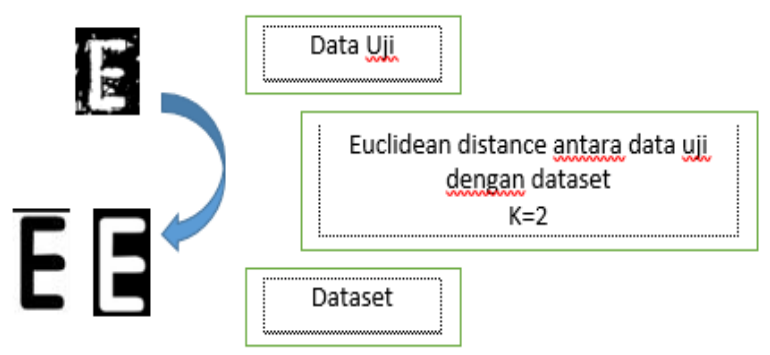

Gambar 6. Analogi KNN dengan $\mathrm{K}=2$

Dari gambar 6 di atas jelas terlihat bahwa data uji huruf E memiliki Euclidean 2 dengan huruf E yang berada di dalam dataset sehingga ketika melakukan pengujian data maka akan ditemukan hasil Euclidean distance antara data uji dengan data set yaitu 2 .

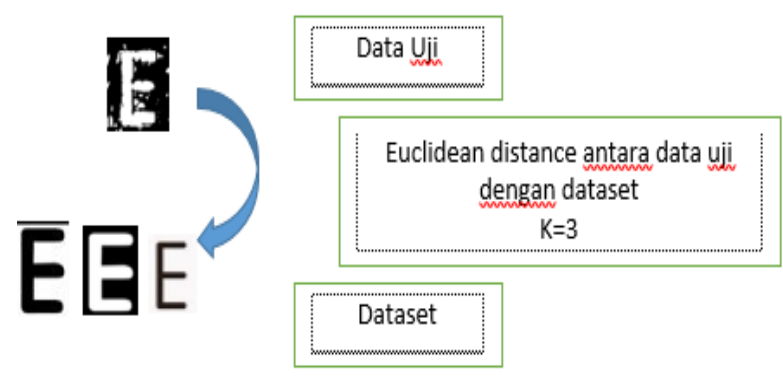

Gambar 7. Analogi KNN dengan $\mathrm{K}=3$

Dari gambar 7 di atas jelas terlihat bahwa data uji huruf E memiliki Euclidean 3 dengan huruf E yang berada di dalam dataset sehingga ketika melakukan pengujian data maka akan ditemukan hasil Euclidean distance antara data uji dengan data set yaitu 3

Dari proses ekstraksi menggunakan metode KNN didapatkan Hasil pengenalan sebagai berikut:

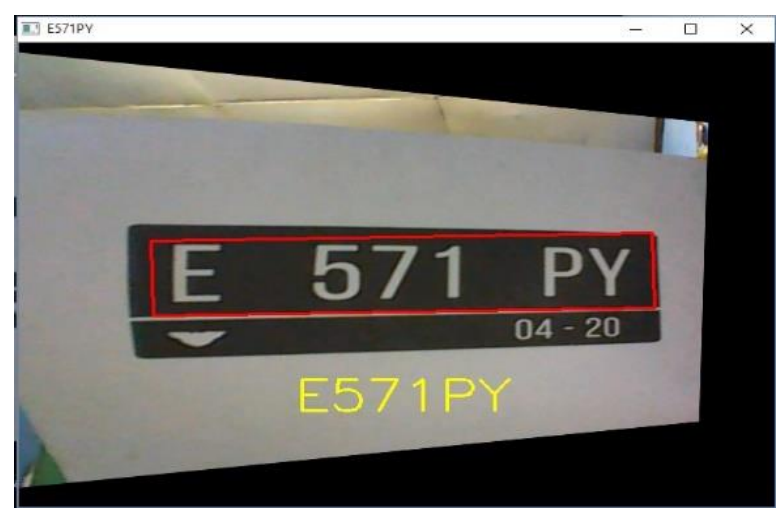

Gambar 8. Deteksi Plat dengan gambar langsung

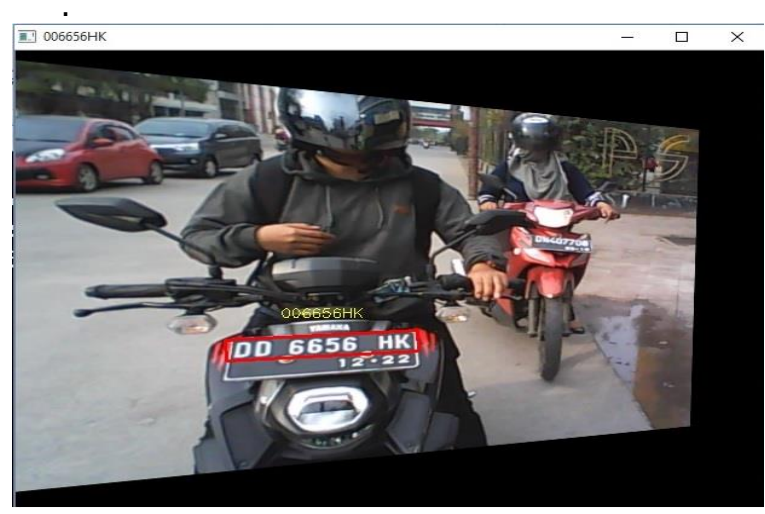

Gambar 9. deteksi plat secara langsung

Pengujian dilakukan pada plat kendaraan dengan kondisi baik dan plat kendaraan dengan kondisi baik dan plat kendaraan dengan kondisi yang kurang baik, dimana setiap plat diuji 4 kali berdasarkan jarak, sudut dan threshold yang diberikan. Pengujian dilakukan menggunakan kamera webcam dengan Raspberry pi spesifikasi prosesor mini. Plat kendaraan yang baik adalah plat kendaraan yang karakter dan bentuk plat tidak rusak (sempurna) dan hanya terdapat sedikit noise ( kotoran ). Sedangkan plat kendaraan yang kurang baik adalah plat kendaraan ang karakter dan bentuk plat tidak sempurna serta memiliki banyak noise atau kotoran pada plat.

\section{b. Hasil Pengujian Plat Kendaraan}

Table 1. hasil pengujian jarak $40 \mathrm{CM}$

\begin{tabular}{rlll}
\hline No & No. Plat & Hasil Pengenalan & KETERANGAN \\
\hline 1 & B 457UTY & B457UTY & SUKSES \\
\hline 2 & DN5269VK & DN5269VK & SUKSES \\
\hline 3 & DD6656HK & DD6656HK & SUKSES \\
\hline 4 & DN4505VT & DN4505VT & SUKSES \\
\hline 5 & DD 5154 KU & DD 5154 KU & SUKSES \\
\hline 6 & DN3742MD & DN3742M0 & GAGAL \\
\hline 7 & DD 3333 YH & DD 3333 YH & SUKSES \\
\hline 8 & DD 1473 YA & DD 1473 YA & SUKSES \\
\hline 9 & DN 4112 YE & DN 4112 YE & SUKSES \\
\hline 10 & DD 5804 CJ & DD 5804 CJ & SUKSES \\
\hline 11 & DN 4879 YC & DN 4879 YC & SUKSES \\
\hline
\end{tabular}




\begin{tabular}{clll}
\hline No & No. Plat & Hasil Pengenalan & KETERANGAN \\
\hline 12 & DD 4353 XY & DD 4353 XY & SUKSES \\
\hline 13 & DN 6330 VM & DN6330VM & GAGAL \\
\hline 14 & B 6703 WJF & B 6703 WJF & SUKSES \\
\hline 15 & DD 9412 XU & DD 9412 XU & SUKSES \\
\hline 16 & DD 5678 NT & DD 5678 NT & SUKSES \\
\hline 17 & DD 6565 BY & DD6565BY & SUKSES \\
\hline 18 & DD 1719 NI & DD1719NI & SUKSES \\
\hline
\end{tabular}

Dari hasil pengujian pada table 4.1 dapat diketahui bahwa persentase rata-rata keakuratan system pengenalan plat kendaraan dengan jarak 40 $\mathrm{CM}$

$$
\frac{\sum(\text { jumlah sukses })}{\sum(\text { jumlah Sampel })}=\frac{16}{18} \times \mathbf{1 0 0 \%}=\mathbf{8 8 , 8 8} \%
$$

Tabel 2 Hasil Pengujian dengan jarak 50 CM

\begin{tabular}{clll}
\hline No & No. Plat & Hasil Pengenalan & KETERANGAN \\
\hline 1 & B 457UTY & B457UTY & SUKSES \\
\hline 2 & DN5269VK & DN5269VK & SUKSES \\
\hline 3 & DD6656HK & DD6656HK & SUKSES \\
\hline 4 & DN4505VT & DN450SVT & GAGAL \\
\hline 5 & DD 5154 KU & DD 5154 KU & SUKSES \\
\hline 6 & DN3742MD & DN3742M0 & GAGAL \\
\hline 7 & DD 3333 YH & DD 3333 YH & SUKSES \\
\hline 8 & DD 1473 YA & DD 1473 YA & SUKSES \\
\hline 9 & DN 4112 YE & DM 4112 YE & GAGAL \\
\hline 10 & DD 5804 CJ & DD 5804 CJ & SUKSES \\
\hline 11 & DN 4879 YC & DN 4879 YC & SUKSES \\
\hline 12 & DD 4353 XY & DD 4353 XY & SUKSES \\
\hline 13 & DN 6330 VM & DN 6330 VM & SUKSES \\
\hline 14 & B 6703 WJF & B 6703 WJF & SUKSES \\
\hline 15 & DD 9412 XU & DD 9412 XU & SUKSES \\
\hline 16 & DD 5678 NT & DD 5678 NT & SUKSES \\
\hline 17 & DD 6565 BY & DD6565BY & SUKSES \\
\hline 18 & DD 1719 NI & DD1719NI & SUKSES \\
\hline & & &
\end{tabular}

Dari table di atas di tentukan tingkat akurasinya dengan menggunakan langkah berikut.

$$
\frac{\sum(\text { jumlah sukses })}{\sum(\text { jumlah Sampel })}=\frac{12}{18} \times \mathbf{1 0 0 \%}=\mathbf{8 5 , 7 1} \%
$$

Table 3 Hasil Pengujian dengan jarak 60 CM

\begin{tabular}{rlll}
\hline No & No. Plat & Hasil Pengenalan & KETERANGAN \\
\hline 1 & B 457UTY & B457UTY & SUKSES \\
\hline 2 & DN5269VK & DN5269VK & SUKSES \\
\hline 3 & DD6656HK & DD6656HK & SUKSES \\
\hline 4 & DN4505VT & DN450SVT & GAGAL \\
\hline 5 & DD 5154 KU & D0 5154 KU & GAGAL \\
\hline 6 & DN3742MD & DN3742M0 & GAGAL \\
\hline 7 & DD 3333 YH & DD 3333 YH & SUKSES \\
\hline 8 & DD 1473 YA & D0 1473 YA & GAGAL \\
\hline 9 & DN 4112 YE & DM 4112 YE & GAGAL \\
\hline 10 & DD 5804 C & DD 5B04 CJ & GAGAL \\
\hline 11 & DN 4879 YC & DN 4879 YC & SUKSES \\
\hline 12 & DD 4353 XY & DD 4353 XY & SUKSES \\
\hline 13 & DN 6330 VM & DN6330VN & GAGAL \\
\hline 14 & B 6703 WJF & B 6703 WJF & SUKSES \\
\hline 15 & DD 9412 XU & DD 9412 XU & SUKSES \\
\hline 16 & DD 5678 NT & D0 5678 NT & SUKSES \\
\hline 17 & DD 6565 BY & DD6565BY & SUKSES \\
\hline
\end{tabular}

\section{DD $1719 \mathrm{NI}$ DD1719NI SUKSES \\ Dari table di atas dapat di tentukan tingkat akurasinya dengan menggunakan persamaan berikut : $\frac{\sum(\text { jumlah sukses })}{\sum(\text { jumlah Sampel })}=\frac{10}{18} \times \mathbf{1 0 0} \%=\mathbf{5 5 , 5 5 \%}$}

Adapun faktor-faktor lain yang menyebabkan kegagalan proses pengenalan plat kendaraan adalah noise yang ada pada plat kendaraan. Penggunaan threshold yang kecil belum mampu menghilangkan noise dengan baik sehingg menyebabkan proses karakter tidka tersegmentasi dengan baik. Sedangkan penggunaan threshold yang tinggi juga mempengaruhi proses pengenalan karakter, walaupun noise dapat dihilangkan akan tetapi berpengaruh pada penitisan lebar dari karakter, sehingg akan menyebabkan prubahan bentuk karakter sperti pada karakter $\mathrm{N}$ dan $\mathrm{H}, \mathrm{S}$ dan 5 , B dan 8 dan $\mathrm{D}$ dan 0.

\section{SIMPULAN DAN SARAN}

\section{Simpulan}

Dari hasil peneltian yang telah dilakukan pada citra plat nomor kendaraan pribadi (plat nomor warn hitam ) dengan menggunakan metode KNearest Neighbour dapat diperoleh kesimpulan sebagai berikut: Citra dapat diidentifikasi jika cahaya yang ada pada citra tidak terllau besar maupun kecacatan tidak terllu parah Karena akan menimbulkan kesalahan dalam identifikasi. Dalam pengidentifikasian citra dibutuhkan banyak data set sehingga dalam pengidentifikasian tidak terjadi kesalahan Karena dalam proses pengidentifikasian ini mencari kemiripam dengan data set yang mirip dengan data set yang sudah ada jika tidak ditemukan maka akan terbaca sebagai data set yang lain sehingga terjadi kesalahan. Hal ini merupakan karakter dari metode K-Nearest neighbor. Dalam proses ini dperoleh tingkat akurasi sebesar $88 \%$ dengan jarak $40 \mathrm{CM}$ dan akurasi $85 \%$ dengan jark 50 CM dan $55 \%$ dengan jarak $60 \mathrm{CM}$. Penggunaan metode k-nearest neighbor lebih tepat Karena metode ini tidak tidak melakukan perulangan dalam proses pencocokan sehingga lebih efisien dalam melakukan pengujian.

\section{Saran}

Perlu adanya penetapan nilai threshold yang baik untuk menangani tingkat noise yang ada pada plat serta pencahayaan pada plat sehingga karakter pada plat kendaraan dapat tersegmentasi dengan 
baik. Sistem ini perlu dikembangkan lebih lanjut sehingga nantinya mampu memberikan hasil yang lebih baik dalam pengenalan karakter sehingga dapat diimplementasikan pada system transportasi

\section{DAFTAR REFERENSI}

Budianto, A., Ariyuana, R., \& Maryono, D. (2018). PERBANDINGAN K-NEAREST NEIGHBOR (KNN) DAN SUPPORT VECTOR MACHINE (SVM) DALAM PENGENALAN KARAKTER PLAT KENDARAAN BERMOTOR. JIPTEK: Jurnal Ilmiah Pendidikan Teknik Dan Kejuruan, 11(1).

https://doi.org/10.20961/JIPTEK.V11I1.18018

Fadila, A. (2017). TINGKAT KESADARAN BERLALU LINTAS PENGENDARA SEPEDA MOTOR DI SURABAYA SELATAN. Kajian Moral Dan Kewarganegaraan, 5(3), 10361051. Retrieved from https://jurnalmahasiswa.unesa.ac.id/index.php/ju rnal-pendidikan-

kewarganegaraa/article/view/22055

Fauziah, S., Sulistyowati, D. N., \& Asra, T. (2019). OPTIMASI ALGORITMA VECTOR SPACE MODEL DENGAN ALGORITMA KNEAREST NEIGHBOUR PADA PENCARIAN JUDUL ARTIKEL JURNAL. Jurnal Pilar Nusa Mandiri, 15(1), 21-26. https://doi.org/10.33480/pilar.v15i1.27
Ruslianto, I., \& Harjoko, A. (2013). Pengenalan Karakter Plat Nomor Mobil Secara Real Time. IJEIS (Indonesian Journal of Electronics and Instrumentation Systems), 1(2), 101-110. https://doi.org/10.22146/ijeis.1967

Sari, M. I. (2011). Desain Segmentasi dan Pengenalan Karakter pada Plat Nomor Kendaraan. In Konferensi Nasional ICT-M Politeknik Telkom (pp. 250-253). Politeknik TELKOM. Retrieved from

http://journals.telkomuniversity.ac.id/knip/articl e/view/556 